\title{
Variáveis dimensionais de sementes de soja que influenciam o processo de semeadura
}

\author{
Sérgio R. dos Santos ${ }^{1}$, Pedro H. Weirich Neto ${ }^{2}$, Emerson Fey ${ }^{3}$ \& Celso Wobeto ${ }^{1}$ \\ ${ }^{1}$ FAPA-PR. Colônia Vitória, Dist. de Entre Rios, CEP 85139-400, Guarapuava, PR. Fone: (42) 625-8395. E-mail: sergior@agraria.com.br (Foto) \\ ${ }^{2}$ UEPG/Lama. Pr. Santos Andrade s/n, CEP 84010-330, Ponta Grossa, PR. Fone: (42) 220-3092. E-mail: Iama1@uepg.br \\ ${ }^{3}$ UNIOESTE. Marechal Cândido Rondon, PR. Fone: (45) 254-3216, Ramal: 218
}

Protocolo 182 - 27/12/2001 - Aprovado em 20/2/2003

\begin{abstract}
Resumo: No processo de semeadura de soja (Glycine max (L.) Merrill), as semeadoras de precisão comumente utilizadas são as dotadas de mecanismo dosador tipo disco perfurado horizontal. Com vistas a um processo de semeadura eficiente, deve-se levar em consideração a velocidade e a homogeneidade das sementes entre outros. $\mathrm{O}$ objetivo deste trabalho foi estudar a influência das variáveis dimensionais das sementes de soja sobre a qualidade de semeadura. Para isto, foram usados uma semeadora de precisão, três cultivares de soja e quatro discos dosadores de náilon, submetidos a cinco velocidades de deslocamento. Como variáveis dependentes, analisou-se a porcentagem de enchimento do disco dosador e a porcentagem de danos físicos perceptíveis visualmente nas sementes. Com o intuito de se estimar o enchimento e a porcentagem de danos físicos causados às sementes, procedeu-se ao ajuste de um modelo pelo método "best subsets". Pode-se visualizar que tanto a diferença das variáveis dimensionais (comprimento e largura) entre as sementes e os orifícios dos discos, quanto a velocidade e o coeficiente de variação, influenciaram a porcentagem de enchimento dos discos dosadores.
\end{abstract}

Palavras-chave: Glycine max, sementes de soja, semeadora de precisão, discos dosadores

\section{Influence of soybean seed size in seeding processes}

\begin{abstract}
In the soybean seeding (Glycine max (L.) Merrill) process, the commonly used seed drill is assembled with the perforated horizontal plate type seed metering mechanism. To accomplish an efficient seeding process using metering device parameters such as speed and seed homogeneity should be considered. The objective of this research was to study the influence of the soybean seed dimensional variables on quality of seeding. For the purpose, a precision seed drill with four horizontal dosing plates and three soybean cultivars were used along with five speeds. The dependent variables were percentage of disc cell filling and percentage of the physical damage to seed. The best subsets method, is Minitab software, which adjusted well to the experimental data. It was concluded that speed, seed size, coefficient of variation and the difference between seed size (length and width) and plate cells influenced the percentage of disc cell filling.
\end{abstract}

Key words: Glycine max, soybean seeds, planters, and horizontal plates

\section{INTRODUÇÃO}

Além dos fatores edafoclimáticos, a população de plantas de soja (Glycine max (L.) Merrill) torna-se fator preponderante para obtenção de altos rendimentos (Gaudêncio et al., 1990). Todavia, para Torres \& Garcia (1991) não só o excesso de plantas, mas, também, as falhas maiores que 0,30 m ocasionam a queda de rendimento em lavouras, sendo estas falhas provenientes de características relacionadas às semeadoras, ou pela interação de fatores, principalmente os relacionados às sementes e ao preparo do solo.

Trabalhando com a homogeneidade de sementes, Krzyzanowski et al. (1991) citam que houve efeito positivo quanto à precisão de semeadura de soja para o mecanismo dosador tipo cilindro canelado, quando as sementes passaram por um sistema de classificação, porém, comparando-se este mecanismo com o de disco horizontal perfurado, o último apresentou-se com maior precisão, independentemente da classificação das sementes.

Considerando-se a população de plantas como um dos quesitos de avaliação de um processo de semeadura, ela poderá estar sendo influenciada pela máquina, mão-de-obra, meio, método e material (Weirich Neto, 1999). Visualizando-se apenas o método, este, numa visão pontual, estará dividido em regulagens e velocidade de semeadura. Esta última, de acordo com Delafosse (1986), é a responsável pelo excesso ou falta de plantas e pela desuniformidade de distribuição. Torn et al. (1996) 
avaliando uma semeadora de fluxo contínuo em três diferentes velocidades de semeadura, três aberturas de comportas e quatro espaçamentos, observaram que o aumento da densidade foi afetado tanto pela abertura da comporta quanto pela velocidade. Fey (1998) avaliando a distribuição e danos nas sementes de três cultivares de soja, sob discos dosadores de náilon com diferentes velocidades tangenciais variando de 0,14 a $0,36 \mathrm{~m} \mathrm{~s}^{-1}$, verificou que nem o fator disco nem o fator velocidade influenciaram os danos físicos e fisiológicos às sementes.

Avaliando o comportamento de três semeadoras com diferentes mecanismos dosadores em duas velocidades de avanço sobre danos mecânicos e fisiológicos em sementes de soja, Boller et al. (1991) concluíram que a porcentagem de sementes quebradas foi influenciada tanto pelos mecanismos quanto pelas velocidades, destacando-se negativamente o disco dosador de ferro fundido com maior porcentagem de quebra de sementes, em relação aos mecanismos tipo cilindro canelado e copo dosador. Destacaram, também, que o mecanismo de rotor canelado quebrou mais sementes a 9,0 que a $6,0 \mathrm{~km} \mathrm{~h}^{-1}$, tendo-se o copo dosador apresentando menor porcentagem de quebra nas duas velocidades. Analisando o efeito de danificações mecânicas causadas por semeadoras em sementes de soja, Razera (1979) constatou aumento na intensidade de danos mecânicos nas sementes com o aumento da velocidade.

Comparando oito semeadoras-adubadoras de milho (Zea mays L.) com relação a preços de aquisição e eficiência operacional, Rocha et al. (1992) analisaram o sistema de distribuição de sementes, em três velocidades de deslocamento das semeadoras e observaram que não houve diferença significativa com relação à população; entretanto, a semeadora dotada de mecanismo dosador tipo dedos prensores, apresentou-se com melhor desempenho quanto à precisão de semeadura; todavia, os autores relataram que esta precisão de semeadura não justifica o seu elevado preço em relação às semeadoras de disco perfurado horizontal; afirmaram, também, que as semeadoras dotadas de sistemas de distribuição tipo disco horizontal, apresentaram variação acentuada entre os preços.

Avaliando uma semeadora de precisão, Pacheco et al. (1996), citam que o aumento da velocidade de avanço piorou significativamente o desempenho da semeadora. Para a elaboração deste trabalho, os autores utilizaram sementes de milho, mecanismo dosador tipo disco perfurado horizontal de ferro fundido com furos oblongos e três velocidades de avanço da semeadora $\left(5,0 ; 7,0\right.$ e $\left.9,3 \mathrm{~km} \mathrm{~h}^{-1}\right)$. Desta forma, a porcentagem de enchimento do disco, com o aumento da velocidade de 5,0 para $9,3 \mathrm{~km} \mathrm{~h}^{-1}$ mostrou-se significativa, tendo-se maior porcentagem de enchimento para a velocidade de $5,0 \mathrm{~km} \mathrm{~h}^{-1}$.

Analisando a distribuição longitudinal de sementes de milho de sete conjuntos híbrido/disco dosador em cinco velocidades tangenciais $\left(0,16 ; 0,17 ; 0,18 ; 0,19 \mathrm{e} 0,20 \mathrm{~m} \mathrm{~s}^{-1}\right)$, Santos (1998) verificou que o aumento da velocidade tangencial dos discos dosadores foi o fator que mais influenciou a distribuição longitudinal das sementes.

O objetivo deste trabalho foi estudar, em laboratório, se as variáveis dimensionais das sementes de soja influenciam a qualidade de semeadura, utilizando-se mecanismo dosador tipo disco perfurado horizontal.

\section{MATERIAL E MÉTODOS}

O trabalho foi realizado no Laboratório de Mecanização Agrícola - Universidade Estadual de Ponta Grossa, Lama UEPG, município de Ponta Grossa, Paraná. Foi utilizada uma semeadora de precisão com mecanismo dosador tipo disco perfurado horizontal, marca Semeato ${ }^{1}$, modelo PSE8, ano de fabricação 1996. Utilizaram-se sementes de três cultivares de soja (Glycine $\max (\mathrm{L}$.) Merrill) classificadas no setor de sementes da Cooperativa Agrária Mista de Entre Rios. No caso das cultivares Abyara e CD 203, para as sementes pequenas (P1) foram usadas peneiras de orifícios variando de 5,50 a $6,50 \mathrm{~mm}$; já para as sementes grandes $(\mathrm{P} 2)$ a variação utilizada foi de 6,60 a 7,50 mm, enquanto para a cultivar Embrapa 59, as sementes pequenas (P1) e grandes (P2) foram classificadas com a utilização das peneiras de 6,00 a 7,00 e 7,10 a 8,00 mm, respectivamente. Utilizaram-se quatro discos de náilon, marca Semeato ${ }^{\circledR}{ }^{1}$ e Fankhauser ${ }^{\circledR}{ }^{1}$, disponíveis no setor de peças da Cooperativa (Tabela 1).

Tabela 1. Relação dos discos ensaiados com suas respectivas referências, Semeato (S) e Fankhauser (F)

\begin{tabular}{ll}
\multicolumn{1}{c}{ Disco } & \multicolumn{1}{c}{ Referência } \\
\hline 1.100 orifícios de $7,5 \mathrm{~mm}$ & S 35.12 .00 .25 \\
2. 90 orifícios de $8,0 \mathrm{~mm}$ & F $026.32007 .5-90-5.5$ \\
3.78 orifícios de $9,0 \mathrm{~mm}$ & Semeato 35.12 .00 .24 \\
4.90 orifícios de $9,0 \mathrm{~mm}$ & F $026.32027 .5-90-5.5$ \\
\hline
\end{tabular}

Para simular uma situação próxima à de campo, as sementes foram inoculadas e tratadas com fungicida, sendo $200 \mathrm{~g}$ de inoculantes turfoso (Bradyrhizobium japonicum, Semia 587 e 5019) para $50 \mathrm{~kg}$ de sementes, $17 \mathrm{~g}$ de ingrediente ativo (i.a.) de Thiabendazole mais $70 \mathrm{~g}$ i.a. de Thiran para $100 \mathrm{~kg}$ de sementes (EMBRAPA, 1997).

A semeadora foi regulada em função da população (300.000 sementes ha ${ }^{-1}$ ) considerando-se germinação e deslizamento 100 e $0 \%$, respectivamente. Trabalhou-se com velocidades variando de $5,6,7,8$ e $9 \mathrm{~km} \mathrm{~h}^{-1}\left(1,39,1,67,1,94,2,22\right.$ e $2,50 \mathrm{~m} \mathrm{~s}^{-1}$, respectivamente) com base em informações obtidas com agricultores. O reservatório da unidade semeadora, com capacidade de $40 \mathrm{~L}$ ou aproximadamente $30 \mathrm{kgf}$ de sementes, foi mantido, durante o ensaio, até a metade de sua altura interna, com presença de defletor do tipo chapéu Chinês, visando ao alívio de pressão na interface sementes e mecanismo dosador, sendo o ensaio realizado com a unidade de semeadura nivelada.

Para coleta de dados, suspendeu-se a semeadora deixando-a apoiada em suportes laterais. Sob uma das rodas motoras colocou-se um simulador de velocidades elétrico, conforme Justino (1998) sendo que, por sorteio, definiu-se a unidade de semeadura para coleta das sementes, as quais foram coletadas em sacos plásticos devidamente identificados para posterior contagem e avaliação da danificação física perceptível visualmente (ABNT, 1987) tendo-se um número de seis repetições para cada conjunto velocidade, disco e peneiras trabalhados. Como variáveis dependentes analisou-se a

A citação de marcas não indica recomendação dos autores 
porcentagem de enchimento do disco dosador e a porcentagem de danos físicos perceptíveis visualmente nas sementes que passaram pelo mecanismo dosador.

Para caracterização das variáveis dimensionais (comprimento e largura) das sementes das cultivares, bem como dos orifícios dos discos, mensurou-se uma amostra de 400 sementes e todos os orifícios dos discos trabalhados. Após esta operação, procedeu-se à avaliação de tais medidas, utilizando-se a análise estatística descritiva.

Estimou-se a porcentagem de enchimento e a porcentagem de danos físicos causados às sementes, procedendo-se ao ajuste de um modelo, pelo método do melhor subconjunto de regressão, de acordo com Elian (1988). Neste método, os critérios utilizados para a escolha da melhor equação de regressão, são: maior coeficiente de determinação $\left(\mathrm{R}^{2}\right)$, maior $\overline{\mathrm{R}}^{2}$ ajustado, menor desvio-padrão (s) e baixo $\mathrm{Cp}$; sendo que, para este último, seu valor deve estar próximo ao número das variáveis selecionadas pelo método.

As variáveis regressoras estudadas foram velocidade de deslocamento da semeadora (Vel), diferença média entre os orifícios dos discos e o comprimento das sementes (OC), diferença média entre os orifícios dos discos e a largura das sementes (OL), coeficiente de variação das medidas de comprimento (CVC) e largura (CVL) das sementes. Após o ajuste do modelo pelo método "best subsets", utilizou-se a metodologia descrita por Rojas (1990) para eliminação de pontos discrepantes.

\section{RESULTADOS E DISCUSSÃO}

Como se visualizou no item Material e Métodos e de acordo com as empresas produtoras de discos, estes apresentavam as medidas de 7,5; 8,0 e 9,0 mm, mas após a mensuração dos orifícios dos discos, pode-se notar, pelas medidas de posição e dispersão (Tabela 2), que há problemas com os orifícios.

No caso dos discos três e quatro, a mensuração dos orifícios apresentou valores (média, mediana, moda e máximo) acima de 9,0 mm, sendo que para o disco três os valores são ainda maiores. Também se chama a atenção para o disco dois, que apresentou um CV alto em relação aos demais, o que poderia afetar a distribuição das sementes ao longo da linha de semeadura.

Conforme citado, a Cooperativa Agrária Mista de Entre Rios Ltda classificava as sementes com o intuito de melhorar a qualidade de semeadura da soja.
Tabela 2. Medidas de posição e dispersão dos discos trabalha$\operatorname{dos}(\mathrm{mm})$

\begin{tabular}{lcccc}
\hline \multicolumn{1}{c}{ Parâmetros } & Disco 1 & Disco 2 & Disco 3 & Disco 4 \\
\hline Média & 7,58 & 7,92 & 9,15 & 9,06 \\
Mediana & 7,60 & 8,00 & 9,15 & 9,05 \\
Moda & 7,60 & 8,00 & 9,15 & 9,05 \\
Desvio Padrão & 0,053 & 0,150 & 0,061 & 0,075 \\
Amplitude & 0,40 & 0,60 & 0,25 & 0,60 \\
Mínimo & 7,30 & 7,50 & 9,05 & 8,55 \\
Máximo & 7,70 & 8,10 & 9,30 & 9,15 \\
CV\% & 0,70 & 1,90 & 0,66 & 0,83 \\
\hline
\end{tabular}

Com relação às medidas das sementes, pode-se verificar, na Tabela 3, que as sementes da cultivar Abyara P2 ficaram dentro dos limites de classificação efetuada pela Unidade de Beneficiamento de Sementes (UBS) da Cooperativa, tendo-se também uma baixa amplitude. A respeito do coeficiente de variação do comprimento das sementes (CVC), as cultivares Embrapa 59 e CD 203, ambas P1, apresentaram-se com os maiores valores. Levando-se em conta o $\mathrm{CV}$, tanto do comprimento quanto da largura das sementes, como fonte de visualização de homogeneidade, pode-se dizer que as sementes das cultivares citadas anteriormente apresentaram problemas de classificação. De acordo com Dengler (1998) ${ }^{1}$ essas cultivares sofreram problemas com longos períodos chuvosos no momento da colheita afetando, assim, sua integridade física (comprimento e largura) porém não afetando a integridade fisiológica das sementes.

Após se obter a diferença entre os orifícios dos discos e o comprimento e entre a largura das sementes, procedeu-se à análise descritiva (Tabela 4) na qual se chama a atenção para a moda do comprimento das sementes, apresentando valores iguais a zero e auxiliando a explicar a falta de enchimento dos discos dosadores. Também auxiliaria, ainda, na escolha do disco no momento da semeadura. Quando ocorreu o valor zero entre a diferença dos orifícios e o comprimento das sementes para a moda, o enchimento apresentou valores inferiores a $90 \%$.

A respeito do modelo utilizado para estimar a porcentagem de enchimento e se considerando o método do melhor subconjunto de regressão (Tabela 5) as variáveis independentes que propiciaram melhor ajuste, foram: velocidade de deslocamento da semeadora (Vel), diferença média entre os orifícios dos discos e o comprimento das sementes (OC), diferença média entre os

Dengler, R.U. Comunicação pessoal.Gerente do setor de classificação e beneficiamento de sementes da Cooperativa Agrária Mista de Entre Rios - Entre Rios, Colônia Vitória, Guarapuava, Paraná

Tabela 3. Medidas de posição e dispersão do comprimento (C) e largura (L) das sementes das cultivares trabalhadas, em milímetro $(\mathrm{mm})$

\begin{tabular}{|c|c|c|c|c|c|c|c|c|c|c|c|c|}
\hline \multirow{3}{*}{$\begin{array}{l}\text { Medidas de Posição } \\
\text { e Dispersão }\end{array}$} & \multicolumn{12}{|c|}{ Cultivares de Soja } \\
\hline & \multicolumn{2}{|c|}{ Abyara P1 } & \multicolumn{2}{|c|}{ Abyara P2 } & \multicolumn{2}{|c|}{ EMBRAPA 59 P1 } & \multicolumn{2}{|c|}{ EMBRAPA 59 P2 } & \multicolumn{2}{|c|}{ CD 203 P1 } & \multicolumn{2}{|c|}{ CD 203 P2 } \\
\hline & $\mathrm{C}$ & $\mathrm{L}$ & $\mathrm{C}$ & $\mathrm{L}$ & $\mathrm{C}$ & $\mathrm{L}$ & $\mathrm{C}$ & $\mathrm{L}$ & $\mathrm{C}$ & $\mathrm{L}$ & $\mathrm{C}$ & $\mathrm{L}$ \\
\hline Média & 6,74 & 6,06 & 7,26 & 6,63 & 7,14 & 6,51 & 7,45 & 6,89 & 7,18 & 6,38 & 7,84 & 6,84 \\
\hline Mediana & 6,75 & 6,10 & 7,25 & 6,65 & 7,15 & 6,55 & 7,45 & 6,90 & 7,15 & 6,40 & 7,85 & 6,85 \\
\hline Moda & 7,00 & 6,20 & 7,25 & 6,55 & 7,25 & 6,60 & 7,50 & 6,90 & 7,00 & 6,40 & 7,75 & 7,00 \\
\hline Desvio padrão & 0,32 & 0,27 & 0,33 & 0,25 & 0,36 & 0,25 & 0,35 & 0,31 & 0,45 & 0,27 & 0,43 & 0,32 \\
\hline Amplitude & 2,20 & 2,10 & 1,75 & 1,65 & 2,30 & 1,45 & 2,25 & 2,10 & 2,55 & 2,30 & 2,95 & 2,20 \\
\hline Mínimo & 5,55 & 5,00 & 6,35 & 5,60 & 6,00 & 5,60 & 6,35 & 5,75 & 6,15 & 5,00 & 6,35 & 5,75 \\
\hline Máximo & 7,75 & 7,10 & 8,10 & 7,25 & 8,30 & 7,05 & 8,60 & 7,85 & 8,70 & 7,30 & 9,30 & 7,95 \\
\hline CV\% & 4,68 & 4,44 & 4,55 & 3,84 & 5,09 & 3,86 & 4,68 & 4,53 & 6,27 & 4,25 & 5,43 & 4,66 \\
\hline
\end{tabular}


Tabela 4. Medidas de posição e dispersão da diferença entre os orifícios dos discos (D1, D2, D3 e D4) e o comprimento e a largura das sementes das cultivares (Abyara (Ab), Embrapa 59 (Em) e CD 203 (CD)) com suas respectivas peneiras (P1 e P2)

\begin{tabular}{|c|c|c|c|c|c|c|c|c|}
\hline \multirow{2}{*}{ Tratamentos } & \multicolumn{4}{|c|}{ Comprimento (mm) } & \multicolumn{4}{|c|}{ Largura (mm) } \\
\hline & $\bar{X}$ & $\mathrm{Md}$ & Mo & $\mathrm{Am}$ & $\overline{\mathrm{X}}$ & $\mathrm{Md}$ & Mo & $\mathrm{Am}$ \\
\hline D1 Ab P1 & 0,84 & 0,83 & 0,75 & 2,15 & 1,52 & 1,48 & 1,35 & 2,05 \\
\hline D2 Ab P1 & 1,18 & 1,20 & 1,00 & 2,50 & 1,18 & 1,85 & 2,00 & 2,10 \\
\hline D3 Ab P1 & 2,41 & 2,40 & 2,30 & 2,05 & 3,10 & 3,05 & 3,10 & 2,10 \\
\hline D4 Ab P1 & 2,31 & 2,30 & 2,05 & 2,20 & 3,00 & 2,95 & 2,95 & 2,10 \\
\hline $\mathrm{D} 1 \mathrm{Ab} P 2$ & 0,35 & 0,35 & 0,00 & 1,25 & 0,95 & 0,95 & 1,00 & 1,70 \\
\hline D2 Ab P2 & 0,66 & 0,70 & 0,00 & 1,60 & 1,29 & 1,30 & 1,40 & 1,90 \\
\hline D3 Ab P2 & 1,89 & 1,90 & 2,10 & 1,80 & 2,52 & 2,50 & 2,50 & 1,60 \\
\hline D4 Ab P2 & 1,79 & 1,85 & 1,85 & 1,80 & 2,43 & 2,45 & 2,40 & 1,65 \\
\hline D1 Em P1 & 0,46 & 0,43 & 0,00 & 1,60 & 1,06 & 1,05 & 1,00 & 1,55 \\
\hline D2 Em P1 & 0,78 & 0,80 & 0,75 & 1,75 & 1,40 & 1,40 & 1,40 & 1,70 \\
\hline D3 Em P1 & 2,01 & 2,00 & 2,25 & 2,15 & 2,64 & 2,60 & 2,60 & 1,55 \\
\hline D4 Em P1 & 1,91 & 1,90 & 1,90 & 2,30 & 2,54 & 2,50 & 2,45 & 1,80 \\
\hline D1 Em P2 & 0,21 & 0,10 & 0,00 & 1,25 & 0,69 & 0,68 & 0,75 & 1,80 \\
\hline D2 Em P2 & 0,49 & 0,45 & 0,00 & 1,75 & 1,03 & 1,00 & 1,00 & 2,20 \\
\hline D3 Em P2 & 1,70 & 1,70 & 1,70 & 2,30 & 2,26 & 2,25 & 2,25 & 2,15 \\
\hline D4 Em P2 & 1,61 & 1,60 & 1,55 & 2,35 & 2,17 & 2,15 & 2,15 & 2,05 \\
\hline D1 CD P1 & 0,45 & 0,43 & 0,00 & 1,40 & 1,19 & 1,20 & 1,00 & 2,15 \\
\hline D2 CD P1 & 0,76 & 0,75 & 0,00 & 1,80 & 1,53 & 1,55 & 1,45 & 2,60 \\
\hline D3 CD P1 & 1,98 & 2,03 & 2,15 & 2,55 & 2,77 & 2,75 & 1,85 & 2,35 \\
\hline D4 CD P1 & 1,88 & 1,90 & 2,05 & 2,55 & 2,67 & 2,65 & 2,65 & 2,30 \\
\hline D1 CD P2 & 0,06 & 0,00 & 0,00 & 1,25 & 0,74 & 0,70 & 0,75 & 1,70 \\
\hline D2 CD P2 & 0,22 & 0,10 & 0,00 & 1,45 & 1,08 & 1,05 & 1,05 & 2,20 \\
\hline D3 CD P2 & 1,31 & 1,35 & 1,25 & 2,90 & 2,31 & 2,30 & 2,25 & 2,30 \\
\hline D4 CD P2 & 1,22 & 1,25 & 1,30 & 2,70 & 2,21 & 2,20 & 2,05 & 2,20 \\
\hline
\end{tabular}

Obs.: $\bar{X}$ - Média; Md - Mediana; Mo - Moda e Am. - Amplitude

orifícios dos discos e a largura das sementes (OL) e coeficiente de variação das medidas de comprimento (CVC). Esta escolha foi efetuada em função do $\mathrm{R}^{2}, \overline{\mathrm{R}}^{2}$ ( $\mathrm{R}^{2}$ ajustado), Cp e do desvio padrão (s). Assim devido aos valores apresentados na Tabela 5 , as quatro variáveis citadas foram as escolhidas para representar o comportamento dos dados.

Tabela 5. Número de variáveis $(\mathrm{N})$ escolhidas pelo método do melhor subconjunto de regressão em função do valores de $\mathrm{r}^{2}, \overline{\mathrm{R}}^{2}$ ( $\mathrm{R}^{2}$ ajustado), $\mathrm{Cp}$, s para estimar o enchimento dos discos dosadores

\begin{tabular}{rccrcccccc}
\hline $\mathrm{N}$ & $\mathrm{R}^{2}$ & $\overline{\mathrm{R}}^{2}$ & \multicolumn{1}{c}{$\mathrm{Cp}$} & $\mathrm{s}$ & $\mathrm{Vel}$ & $\mathrm{OC}$ & OL & $\mathrm{CVC}$ & $\mathrm{CVL}$ \\
\hline 1 & 0,551 & 0,550 & 223,5 & 9,252 & & $\mathrm{x}$ & & & \\
1 & 0,544 & 0,543 & 234,7 & 9,321 & & & $\mathrm{x}$ & & \\
2 & 0,683 & 0,682 & 5,1 & 7,777 & $\mathrm{x}$ & $\mathrm{x}$ & & & \\
2 & 0,674 & 0,673 & 20,0 & 7,886 & $\mathrm{x}$ & & $\mathrm{x}$ & & \\
3 & 0,684 & 0,682 & 5,4 & 7,772 & $\mathrm{x}$ & $\mathrm{x}$ & $\mathrm{x}$ & & \\
3 & 0,684 & 0,682 & 6,4 & 7,779 & $\mathrm{x}$ & $\mathrm{x}$ & & & $\mathrm{x}$ \\
4 & 0,686 & 0,684 & 4,0 & 7,754 & $\mathrm{x}$ & $\mathrm{x}$ & $\mathrm{x}$ & $\mathrm{x}$ & \\
4 & 0,684 & 0,682 & 7,4 & 7,779 & $\mathrm{x}$ & $\mathrm{x}$ & $\mathrm{x}$ & & $\mathrm{x}$ \\
5 & 0,686 & 0,683 & 6,0 & 7,761 & $\mathrm{x}$ & $\mathrm{x}$ & $\mathrm{x}$ & $\mathrm{x}$ & $\mathrm{x}$ \\
\hline
\end{tabular}

A análise de regressão múltipla apresentou-se significativa $(\mathrm{p}<0,05)$ com coeficiente de determinação $\left(\mathrm{R}^{2}\right)$ ajustado em 0,684 . Verificando-se que havia pontos discrepantes, eliminaram-se os mesmos, de acordo com Rojas (1990); em seguida, realizou-se uma nova análise de regressão, obtendo-se um novo $\mathrm{R}^{2}$ ajustado de 0,705 , o qual indica que $70,5 \%$ do comportamento do fenômeno podem ser explicados pela equação obtida.
Com relação à equação que representaria o modelo de regressão, todas as variáveis se apresentaram significativas. No caso da variável velocidade (Vel) o sinal negativo do termo visualizado na Eq. 1 indica que, aumentando-se tal variável, tem-se a redução da porcentagem de enchimento e, conseqüentemente, a redução da população desejada, concordando com Pacheco et al. (1996).

$\%$ Enchimento $=114-3,66 \mathrm{Vel}+7,13 \mathrm{OC}+7,55 \mathrm{OL} 1,27 \mathrm{CVC}$

Quanto à diferença média entre os orifícios e o comprimento (OC) e largura (OL) das sementes, como já se esperava, o aumento desta diferença resultará numa porcentagem maior de enchimento.

A respeito do coeficiente de variação do comprimento das sementes e de acordo com a equação, a medida em que tal CVC aumenta, menor é a porcentagem de enchimento; então, considerando o $\mathrm{CV}$ como medida de uniformidade do tamanho das sementes, quanto maior for este valor, mais heterogêneas serão as sementes. Desta forma, ter-se-ão maiores problemas com a obtenção da população recomendada, a qual, segundo Gaudêncio et al. (1990) e Torres \& Garcia (1991) é fator relevante quando se deseja altos rendimentos.

Com relação ao modelo utilizado para se estimar a porcentagem de danos físicos visíveis pelo método do melhor subconjunto de regressão, as variáveis independentes escolhidas (Tabela 6) foram as mesmas que representaram o modelo para estimar a porcentagem de enchimento do disco dosador. Efetuando-se a análise de regressão, esta se apresentou significativa $(\mathrm{p}<0,05)$; no entanto, o coeficiente de determinação ajustado apresentou valor de 0,163 , mesmo com a eliminação dos pontos discrepantes. Desta forma, pelo baixo valor do $\mathrm{R}^{2}$ ajustado, o modelo (Eq. 2) não seria aplicado para explicar o comportamento dos dados.

Tabela 6. Número de variáveis (N) escolhidas pelo método do melhor subconjunto de regressão em função do valores de $r^{2}, \bar{R}^{2}$ ( $R^{2}$ ajustado), Cp, s para estimar a porcentagem de danos físicos visíveis

\begin{tabular}{|c|c|c|c|c|c|c|c|c|c|}
\hline $\mathrm{N}$ & $\mathrm{R}^{2}$ & $\overline{\mathrm{R}}^{2}$ & $\mathrm{Cp}$ & $\mathrm{S}$ & Vel & $\mathrm{OC}$ & OL & CVC & CVL \\
\hline 1 & 0,052 & 0,050 & 90,6 & 2,823 & & $\mathrm{x}$ & & & \\
\hline 1 & 0,051 & 0,050 & 91,0 & 2,823 & & & $\mathrm{x}$ & & \\
\hline 2 & 0,104 & 0,102 & 47,9 & 2,744 & $\mathrm{x}$ & $\mathrm{x}$ & & & \\
\hline 2 & 0,102 & 0,099 & 50,0 & 2,749 & $\mathrm{x}$ & & $\mathrm{x}$ & & \\
\hline 3 & 0,152 & 0,150 & 7,8 & 2,669 & $\mathrm{x}$ & $\mathrm{x}$ & $x$ & & \\
\hline 3 & 0,142 & 0,138 & 18,2 & 2,688 & $\mathrm{x}$ & $\mathrm{x}$ & & & $\mathrm{x}$ \\
\hline 4 & 0,160 & 0,156 & 4,1 & 2,661 & $x$ & $\mathrm{x}$ & $\mathrm{x}$ & $\mathrm{x}$ & \\
\hline 4 & 0,154 & 0,149 & 9,8 & 2,671 & $\mathrm{x}$ & $\mathrm{x}$ & $\mathrm{x}$ & & $\mathrm{x}$ \\
\hline 5 & 0,161 & 0,155 & 6,0 & 2,662 & $\mathrm{x}$ & $\mathrm{x}$ & $\mathrm{x}$ & $\mathrm{x}$ & $\mathrm{x}$ \\
\hline
\end{tabular}

em que, $\% \mathrm{DFV}$ - danos físicos visuais, $\%$.

\section{CONCLUSÕES}

1. Pelo método do melhor subconjunto de regressão, a diferença das variáveis dimensionais (comprimento e largura) 
entre os orifícios dos discos e a velocidade e o coeficiente de variação do comprimento das sementes está influenciando a porcentagem de enchimento dos discos dosadores.

2. Quanto maior for a diferença das variáveis dimensionais entre os orifícios dos discos, maior também será a porcentagem de enchimento.

3. Quanto maior a velocidade de deslocamento e o coeficiente de variação do comprimento das sementes, menor será a porcentagem de enchimento dos discos dosadores.

\section{LITERATURA CITADA}

ABNT - Associação Brasileira de Normas Técnicas. NBR/9743 - Semeadora de fluxo contínuo em linha - Ensaio de laboratório. São Paulo: Fórum Nacional de Normalização, 1987. 16p.

Boller, W.; Gazola, O.; Severo, J, L.; Berber, D, C.; Squilljee, E. Avaliação dos efeitos de mecanismos dosadores de semeadoras sobre danos mecânicos e fisiológicos em sementes de soja (Glycine max L. Merrill). In: Congresso Brasileiro de Engenharia Agrícola, 20, 1991, Londrina. Trabalhos apresentados... Londrina: SBEA, 1991. 1181-1192p.

Delafosse, R.M. Máquinas semeadoras de grano grueso. Santiago: Oficina Regional de La FAO para América Latina \& Caribe, 1986. 48p.

Elian, S.N. Análise de regressão. São Paulo: Universidade de São Paulo - Instituto de Matemática e Estatística - Departamento de Estatística, 1988, 232p.

EMBRAPA - Empresa Brasileira de Pesquisa Agropecuária. Recomendações técnicas para a cultura da soja no Paraná 1996/ 1997. Londrina: EMBRAPA-CNPSo, 1997.236p. Documentos, 131

Fey, E. Avaliação da distribuição e danos nas sementes de soja (Glycine max (L.) Merrill), sob cultivares e discos, com diferentes velocidades tangenciais do disco dosador. Ponta Grossa: UEPG, 1998. 45 p. Monografia Graduação

Gaudêncio, C.; Gazziero, D.L.P.; Jaster, F.; Wobeto, C. População de plantas de soja no sistema de semeadura direta para o Centro-Sul do Paraná. Londrina: EMBRAPA-CNPS, 1990. 4p. Comunicado Técnico, 47
Justino, A. Desempenho do mecanismo dosador de disco perfurado horizontal na distribuição de sementes de milho (Zea mays L.) em sistema de plantio direto. Botucatu: UNESP, 1998. 140p. Tese Doutorado

Krzyzanowski, F.C.; França Neto, J.B.; Costa, N.P. Efeito da classificação de sementes de soja (Glycine max (L.) Merrill) por tamanho sobre a qualidade e a precisão de semeadura. Revista Brasileira de Sementes, Brasília, v.13, p.59-68, 1991.

Pacheco, E.P.; Mantovani, E. C.; Mertyn, P.J.; Oliveira, A.C. Avaliação de uma semeadora - adubadora de precisão. Pesquisa Agropecuária Brasileira, Brasília, v.31, n.3, p.209214, 1996.

Razera, L.F. Efeito de danificações mecânicas causadas por semeadoras em sementes de soja (Glycine max (L.) Merrill). Piracicaba: ESALQ/USP, 1979. 67p. Dissertação Mestrado

Rocha, F.E.C.; Mantovani, E.C.; Bertaux, S.; Garcia, J. C. Comparação de semeadoras-adubadoras de milho (Zea mays L.) com relação a preços de aquisição e eficiência operacional. Pesquisa Agropecuária Brasileira, Brasília, v.27, n.5, p.751757, 1992.

Rojas, M.G. Técnicas de diagnóstico em regression lineal. Publicacion Oficial de la Sociedade Chilena de Estatística. $\mathrm{n}^{\circ} 1-2, \mathrm{p} .23-43,1990$.

Santos, S.R. dos. Distribuição longitudinal de sementes de milho (Zea mays L.) de sete conjuntos híbrido/disco em diferentes velocidades tangenciais. Ponta Grossa: UEPG, 1998.50 p. Monografia Graduação

Torn, M.C.; Larrosa, L.A.; Soza, E.L.; Donato de Cobo, L.B. Factores que afectam la densidade de siembra de soja (Glycine $\max$ (L) Merrill), en un dosificador de flujo continuo. In: Congresso Brasileiro de Engenharia Agrícola, 25, 1996. Bauru, Anais... 1996. Bauru: Sociedade Brasileira de Engenharia Agrícola, 1996. CD-Rom

Torres, E.; Garcia, A. Uniformidade de distribuição de plantas em lavouras de soja. Londrina: EMBRAPA-CNPSo, 1991. 9p. Comunicado Técnico, 48

Weirich Neto, P. H. Máquinas agrícolas em sistema de semeadura sob a palha (Plantio direto): Atualização. In: Pauletti, V.; Seganfredo, R. Plantio direto: Atualização tecnológica. Fundação Cargill/Fundação ABC, 1999, 171p. 